\title{
Exploration on Training Practice Ability in DIGITAL LOGIC EXPERIMENT
}

\author{
Shanshan Li, Ninghan Zheng, Chengbin Quan, Yongqiang Chen \\ Department of Computer Science \& Technology, Tsinghua University, Beijing, China
}

\begin{abstract}
The hardware related courses in computer major require a lot of practise on experiment to fully understand the theoretical knowledge for the students. Especially for the first-year or second-year undergraduate students, how to cultivate students' practical ability effectively is the subject of Computer Science in Colleges and Universities. This paper introduces the experimental teaching reform trial of the Digital Logic Circuit courses, and sums up the experience of how to stimulate students' awareness of innovation in the hardware experiment teaching and how to improve the students' practical ability. This paper proposes that we should start the student independent innovation experiment as soon as possible at the university stage. We design the independent innovation experiment in Digital Logic Circuit of the hardware experiment, that experiment is an open-minded experiment. After years of experiments carried out, the students deepened understanding of the knowledge of theory course, improve the interest in the design of hardware, understand the basic processes of the design of electronic products, improve the ability of practical, and establish the consciousness of innovation and practice. Our trial has proved that it is very meaningful and feasible to enhance the ability of innovation practice in the low grade students of computer major.
\end{abstract}

\section{Keywords}

Experimental Teaching; Computer Hardware; Practice Training

\section{INTRODUCTION}

As important as software courses, hardware related courses are the important component in the course of computer science curriculum [1]. From studying of the hardware courses, students will understand the working mechanism of the computer more clearly. At present, most of the computer hardware series courses in colleges and universities have been set up, including Digital Logic, Computer Organization and Architecture, etc.

Theoretical teaching focuses on the knowledge points, while experimental teaching focuses on the application of knowledge. Through the study of computer hardware experiment, we can train students' practical ability, engineering practice ability and the ability of development and innovation [2]. Hardware experiment teaching is an important part of computer hardware course. In order to really achieve the purpose of the experiment, operating the real experimental equipment is needed.

CS2013 raises: Appreciation of the interplay between theory and practice [3]. Undergraduate students of computer science and technology should have practical ability, and understand the interplay between theory and links between them. Graduates of a Computer Science program need to understand how theory and practice influence each other. This also shows we should pay attention to the practice teaching in the whole teaching position.

Hardware courses mainly include Digital Logic, Computer Organization, Computer Architecture, Computer Interface and so on [4]. Digital Logic is the fundamental of these courses and experimental teaching is an important part, which is an indispensable means to cultivate students' practical ability, engineering practice ability and innovation ability.

The computer professional requires many practices, so the experimental teaching is very important in computer professional students training process [5]. Thus we try to stimulate students' innovation consciousness through the practice in the process of experiment teaching.

DOI :10.5121/ijite.2016.5302 
Using the hardware experiment to improve the students' practical hands-on participation, to cultivate their ability of innovation and practice. How to cultivate students' innovative practical ability effectively is the subject of Computer Science in Colleges and Universities, especially for the first-year or second-year undergraduate students. We select the Digital Logic course as a starting point [6]. This course is a compulsory fundamental hardware course for computer professional sophomore in Tsinghua University. We made a lot investigation and research for this course, especially on experimental teaching. We generalized and analysed the old experiment contents, set up the new content, and adopted some new experimental methods, in order to consolidate the students' theoretical knowledge, in the meanwhile cultivate their ability of innovation and practice.

\section{DIGITAL LOGIC EXPERIMENT}

For the computer professional students in sophomore, Digital Logic course is one of the earliest hardware courses they encounter. They have no knowledge of computer hardware, so it need to step by step to make them aware of what the computer hardware is, and thus cause their interest to learn these courses.

And the experimental teaching is an important part in Digital Logic course [7]. The experiments of computer major mainly include following types: the basic verification experiment, the advanced comprehensive experiment, the independent innovation experiment, and etc. In our department, we select following experiments as course experiment, shown in Table 1.

Table 1. Experiments

\begin{tabular}{|l|l|l|}
\hline Experiment & \multicolumn{1}{|c|}{ Description } & \multicolumn{1}{|c|}{ Type } \\
\hline $\begin{array}{l}\text { Instrument } \\
\text { Operation }\end{array}$ & $\begin{array}{l}\text { Learn how to the use of experimental } \\
\text { instruments, including the oscilloscope, } \\
\text { logic analyzer, etc. }\end{array}$ & Basic \\
\hline Chip Measurement & $\begin{array}{l}\text { Measurement of the delay and transmission } \\
\text { characteristics for 74 series chip. }\end{array}$ & Basic \\
\hline Adder & $\begin{array}{l}\text { Assemble the adder circuit using 74 series } \\
\text { chip. }\end{array}$ & Basic \\
\hline Timing Control & $\begin{array}{l}\text { Using 74 series chip to assemble a circuit, } \\
\text { which can control an device with three } \\
\text { period of timing. }\end{array}$ & Advanced \\
\hline Adder/ Counter & $\begin{array}{l}\text { Use hardware description language to } \\
\text { design and implement an adder and a } \\
\text { counter. }\end{array}$ & Basic \\
\hline $\begin{array}{l}\text { Traffic } \\
\text { Lights }\end{array}$ & $\begin{array}{l}\text { Use hardware description language to } \\
\text { design and implement a controller of the } \\
\text { traffic lights. }\end{array}$ & Advanced \\
\hline $\begin{array}{l}\text { Electronic Cipher } \\
\text { Lock }\end{array}$ & $\begin{array}{l}\text { Use hardware description language to } \\
\text { design and implement an electronic cipher } \\
\text { lock. }\end{array}$ & Advanced \\
\hline $\begin{array}{l}\text { Colored LED } \\
\text { Show Originality }\end{array}$ & $\begin{array}{l}\text { Use the light emitting diode or light array to } \\
\text { complete a creative idea experiment. }\end{array}$ & Innovation \\
\hline
\end{tabular}

After learning the basic theoretical knowledge of Digital Logic course, the independent innovation experiment is arranged. This arrangement is mainly based on the following considerations.

- Independent experiment can cultivate students' ability of practice. The basic verification experiments and the advanced comprehensive experiments usually involve only one or several points of knowledge. For the cultivation of innovative consciousness and practical ability, these experiments are obviously deficient. However, the innovative experiment can 
stimulate students' creative thinking and training their practical ability. As long as the experimental difficulty is designed appropriately, it will be of great advantage for cultivating the students' engineering practice ability [8].

- It is a long term work to cultivate students' practice ability. The training process must keep on throughout the whole the course of the university education [9]. Due to the influence of the oriented examination education in primary and secondary schools, the students who just enter universities are often lack of interest and initiative in hardware of computer. Therefore, the students should do the practice training as soon as possible at the university stage, in order to help them to change their inherent thinking formed by the oriented examination education. In the university, we should mobilize the students' enthusiasm of innovation practice first, which will help the students learn the new knowledge more efficient, and help them adapt to the society requirement quickly after graduation [10].

The students in Digital Logic course are just touching the hardware experiment, so the experiment should not be very difficult, and the experiment should have good visible display, thus it can arouse more interest and motivation in students for hardware experiment. So we designed the innovation experiment called Colored LED Show Originality, in which the students should use the LED (light-emitting diodes) or LED array to do a show or other things to display their creative ideas. The implementation can use ready-made circuit board, or the circuit board designed by the students themselves. Design does not need to have a high level in technical content, only need to have enough creativity, to show the concept of hardware design. That is enough for the entrance of the hardware course, which will make the students have the interest for the hardware courses.

In this hardware experiment, the students are required to think the topic themselves, using the knowledge learned in Digital Logic course to design and implement a circuit demonstration device to show their ideas or have some distinctive functions. The experiment requires the students to have their own ideas, but also need them to realize their ideas in practice. This is a good exercise for fostering the students' ability of innovation and practice.

\section{EXPERIMENT TEACHING}

In the course of experiment teaching, the basic experiment content can strengthen the understanding of the students' knowledge. But these experiments lack the creativity of students, students are easy to feel boring for these experiments. It's different for the innovation experiments. Because the experiment contents are thought out by the students themselves, So the students will have much interesting on it, and are willing to do more work on it.

Because the experiment ideas are different, the results of the experiments are various. Good experimental results are welcome of course, but for the independent innovation experiment, the process of the experiment should get more attention. This is because the students' ability of innovation and practice is gradually accumulated in the experiment process. The whole process of the experiment should always around how to inspire the innovative thinking and improve the practice ability.

\subsection{Idea of the Experiment}

The good idea will produce the good experiments. Innovative awareness is by no means without foundation, need to have the accumulation. The students usually pay attention to observation, and have diligent in thinking, or have wide interests of students, they will have more innovative ideas. And the students usually do not pay much attention to this area, through the training in this experiment, it will also let them gradually consciously strengthen the training in this area.

Our innovative experiment wants the student show their ideas through the LED lights. The implement does not need very complex circuit design, but there must be a sufficient display and have innovative ideas. This experiment wants to let the student realize their own ideas through 
the LED lights, and want to cultivate their innovation consciousness and exercise practical ability.

Through the experiment carrying in these years, it is proved that that as long as the students were provided with the independent experiment contents open and free, their creative potential will be fully motivated. Figure 1 . is the students' experiments demonstration, they are fun and full of innovative ideas. For example, they made a model of DNA double helix structure with the LED lights, and this model can show the DNA replication process using the different color lights flashing. Other demonstrations include colored traffic signal lights, Snake game, digital alarm clock, etc.

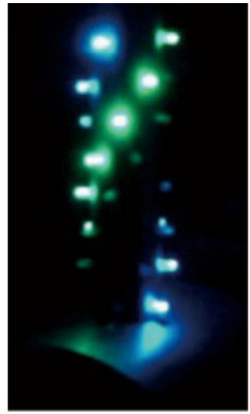

(a) DNA Model

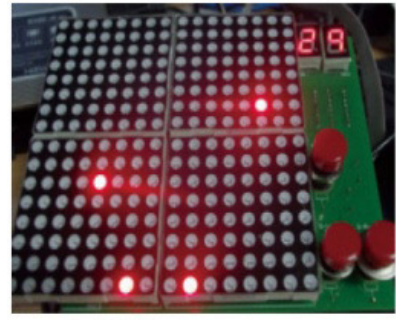

(c) Pick Beans Game

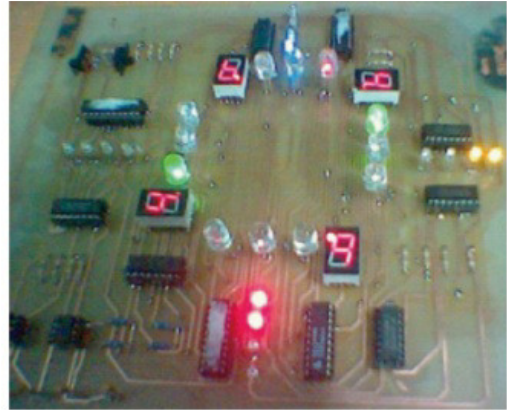

(b) Traffic Loghts

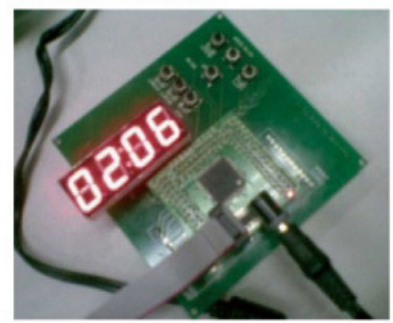

(d) Digital Alarm Clock

Figure 1. Experiments demonstration

In this innovation experiment, we found that the good experiments have the following characteristics:

- It has unique or creative ideas. It chooses some interesting or meaningful things in life to show through the lights, such as the DNA double helix structure, showing its replication process.

- It has innovation in the design or function. It is good at trying to do things that others have not done, such as using the competition mechanism to show which side of the game press the key faster.

- It helps to achieve a good display effect. The show need to be clear and not monotonous, demonstration rich and colorful, such as traffic signal lights, Snake game, etc.

- It need the combination of functional and interesting as far as possible. the pursuit of practical and interesting, such as electronic cube, digital alarm clock, etc.

\subsection{Implement of the Experiment}

Any idea must be based on a certain material and technical basis. We want to let the student implement their creative ideas into the real thing; otherwise, the idea will become a dream.

In the first few years, the experimental equipment and material we provided to the students mainly includes TTL chip and GAL (General Array Logic). The students mainly adopt two ways to realize their design: First is only use TTL devices, the second is mixed with GAL and TTL 
devices. The first way will use what they have learned in course, in the experiment it can consolidate and deepen the understanding of basic knowledge; the second, because of the advantages of GAL devices, the students will use the HDL (Hardware Description Language) to achieve a complex design more easily and will learn more new technologies [11]. Students need to design their own circuit board or using the bread-board to complete the experiment.

From 2012, we provide a control core board for the students in the experiment. This board contains a CPLD (Complex Programmable Logic Device) with many Input/ Output connection pins, which will be used as a universal function board. Using this core board, the students only need to focus on the internal function implement. By writing HDL code and simulation, the students can easily realize the control function. Combined with self-designed display board, the students will get their final implement. At 2014, we designed an experimental board with built-in $128 * 64$ light emitting diode array, and this board has ten chip sockets that can plug in 74 series chips. It also has a CPLD, switch as input and seven segments LED, etc. The students can directly do the experiment on this experiment board.

\subsection{Practice in Experiment}

Practical ability is important for the student. The students of computer professional generally pay more attention to software skill training, but for the ability of hardware practice they do not have enough training. However, to become an outstanding innovative students of computer professional, the students must have good hardware knowledge and skillful practice ability [12]. In hardware experiment, we cultivate students' practical ability mainly from the following two aspects.

In order to improve the students' practical ability, it should encourage the students to practice consciously [13]. If we only focus on learning the basics theory knowledge, overlook the cultivation of this consciousness, the students will miss the valuable opportunity to accumulate the experience for improving the practical ability. In the experiment, the teachers and laboratory only provide some knowledge and technical support, the students are always the dominant in experiment. Compared to the traditional validation experiments, the opening experiment content, independent selection, efforts to complete their own creativity, the students will get higher fulfillment from the experiment, which will promote the students to have more interest and enthusiasm into hands-on practice.

Practical ability improving is a process of gradual accumulation of the experience. In this hardware experiment, students should realize their ideas, in which they will experience the process from the circuit design, simulation and debugging, PCB (Printed Circuit Board) design, to the final implement. This specific steps of the experiment will improve students' practical ability gradually. In the experiment, the students will encounter a variety of practical problems, and some problem maybe not easily found the solution directly from the textbook, the students perhaps take many detours to solve these problems. But it is such a process gives students hands-on practice for a personal experience, accumulated experience, improve the ability to solve specific problems. For example, the students in the PCB board design, should take into account the location of each chip in the circuit board as well as the beauty of the circuit board, and in circuit design they should consider the driving ability of chip pins. These are all the problems only met in the real design. From such an experiment training, the students will get much more experience on hardware design.

After the completion of their own creative products, the students will give a presentation in class, and submit an experiment report. The report must include the design ideas, schematics, printed circuit board diagram or HDL code, and the product demonstrations instructions. Meanwhile the report also must include the problems encountered in the design or debugging and the corresponding solving method. 
The design of this experiment will help students to sum up their own innovation practice experience in a timely manner, and it will be a good inspiration for them to improve their innovation ability in the future engineering practice.

\section{ACHIEVEMENT}

This innovation experiment is not a course required experiment, students can choose whether to do the experiment according to their time and interest. In order to motivate students to do the innovation experiment, we will give additional score points to those who have creative ideas or completed the experiment outstandingly.

In the past five years of experiment teaching in Digital Logic courses, we continuously improve our innovation experiment, and the students have designed and implemented a lot of very creative experimental content. Table 2. is the distinctive experiments in these years.

Table 2. Distinctive Experiments

\begin{tabular}{|l|l|l|}
\hline Year & \multicolumn{1}{|c|}{ Title } & \multicolumn{1}{c|}{ Description } \\
\hline 2011 & DNA Model & $\begin{array}{l}\text { DNA model was made using the LED, showing the } \\
\text { process of DNA replication. }\end{array}$ \\
\hline 2012 & Snakes Game & Implement the game Snake on the LED array. \\
\hline 2013 & Rotated 3D Display & $\begin{array}{l}\text { Let the LED array rotation, display three-dimensional } \\
\text { space graphics, such as a sphere. }\end{array}$ \\
\hline
\end{tabular}

\begin{tabular}{|l|l|l|}
\hline 2014 & Electronic Cube & $\begin{array}{l}\text { The cube six surface are using different color LEDs, } \\
\text { pressing the button stand the rotation of the cube, the } \\
\text { LEDs will change the color. }\end{array}$ \\
\hline 2015 & Battle Game & Similar to the open turret game \\
\hline
\end{tabular}

In the experiments carried out process of these five years, the number of students selecting the innovation experiment were continuously growing, shown in Figure 2. At the first year, only one fifth students selected the innovation experiment, but after several years of efforts, basically all of the students will choose the innovation experiment. The main reason is that the students have been aware of the innovative experiment is not complex to complete, and it has a lot of fun; and there is no denying the fact, bonus score also encourage students to chosen for the experiment.

In the process of the innovation experiment, students will be more interested in, and will put more effort and time on it, so as to learn some new knowledge for it. Students are also very welcome to the innovation experiment, in the students' experiment report it is often mentioned that the experiment can exercise their practical ability, expand thinking. They think this experiment is a very interesting experiment.

\begin{tabular}{|c|c|c|c|c|c|}
\hline \multirow{3}{*}{$\begin{array}{r}200 \\
100 \\
0\end{array}$} & 146 & ${ }^{138}{ }_{65}$ & 14421 & 14736 & 14433 \\
\hline & 琶32 & 琶 65 & & & \\
\hline & 2011 & 2012 & 2013 & 2014 & 2015 \\
\hline E Students & 146 & 138 & 142 & 147 & 144 \\
\hline E Selected & 32 & 65 & 121 & 136 & 133 \\
\hline
\end{tabular}

Figure 2. The student number select the innovation experiments

Because the students selecting this experiment may need the circuit board manufacturing or will buy some chips, they need some financial support from the laboratory. If the circuit board is entirely their own design, basically each student will need $\$ 50$ support. However, because there 
are several types of ready-made experiment device can be chosen, the students can be directly complete the experiment on our equipment provided.

But with the experiments carried out and continuous accumulation in experiment, the students reflect that it is more and more difficult to think out a new experiment that is different from the previous experiments. So the experiment content the students choose, slowly focus to the games, such as pinball, aircraft fighting. We are also introducing a number of new content and equipment, so that the students can have more choice in experiment.

\section{SUMMARY}

We designed the independent innovation experiment in Digital Logic Circuit of the hardware experiment, that experiment is an open-minded experiment. After years of experiments carried out, the students deepened understanding of the knowledge in theory course, improve the interest in the design of hardware, understand the basic processes of the design of electronic products, improve the ability of practical, and establish the consciousness of innovation and practice. Our trial has proved that it is very meaningful and feasible to enhance the ability of innovation practice in the low grade students of computer professional.

\section{ACKNOWLEDGEMENTS}

Thanks are due to professor Yang Shiqiang and Zhao Youjian for assistance in the corresponding theory courses and to professor Liu Weidong for valuable discussion. We gratefully acknowledge the valuable cooperation of Tian Shuzhen in experiment teaching with us and thanks to Gao Yuchao and Sun Yongqian for the work in experiment preparing and checking.

\section{REFERENCES}

[1]. F. Chen, X. Qi and Y. Luo, "Construction and Implementation of Innovation Driven Hierarchical Computer Hardware Courses", University Education,2013,2, pp40-42.

[2]. M. Qi, P. Zhang and C. Dong, "Research and Innovation of Hardware Experiment Teaching", Experiment Science and Technology 02, pp80-81.

[3]. The Joint Task Force on Computing Curricula, Association for Computing Machinery (ACM) and IEEE Computer Society, Computer Science Curricula.2013, http://www.acm.org/education/CS2013-final-report.pdf

[4]. Z.Y. Wang, and X.S. Zhou, "Research on Systematic Ability for Computer Professional Students and Curriculum", Computer Education 9, pp1-6.

[5] M. Bahman and R. Alireza, "The fundamental digital circuits laboratory at the University of Central Florida", ASEE Annual Conference Proceedings, pp. 4985-4988.

[6] B. Cordelia M, P. Dimitrios and L. Greg, "Sophomore-level curriculum innovation in electrical and computer engineering", ASEE Annual Conference and Exposition, Conference Proceedings, 2013.

[7] O. B. Adam, P. Guturu and M. R. Varanasi, "An innovative method of teaching digital system design in an undergraduate electrical and computer engineering curriculum", 2009 IEEE International Conference on Microelectronic Systems Education, MSE 2009, pp. 25-28.

[8] N. Na and D. Hu, "Computer engineering technology program - A curriculum innovation initiative”, 118th ASEE Annual Conference and Exposition, June 26, 2011 - June 29, 2011.

[9] J. Li and Y. Zhou, "The exploration and practice in innovative personnel training of computer science and technology", Proceedings of 2012 International Symposium on Information Technologies in Medicine and Education, ITME 2012, v 1, pp. 385-389.

[10] Fan Wei, Huang Xianying and Xu Shijun, "Thinking on the innovation mode of computer applied talents training", Computer Education, vol 17, 2011, pp.13-15. 
International Journal on Integrating Technology in Education (IJITE) Vol.5, No.3, September 2016

[11] M. Felipe, B. Susana and M. Norberto, "Project based learning experience in VHDL digital electronic circuit design", 2009 IEEE International Conference on Microelectronic Systems Education, MSE 2009, pp. 49-52.

[12] Cifredo-Chacõn, M. D. L Ángeles, Quirõs-Olozábal, Ángel, Guerrero-Rodrígueza and J. María, "Computer architecture and FPGAs: A learning-by-doing methodology for digital-native students", Computer Applications in Engineering Education, v 23, n 3, pp. 464-470.

[13] X. Su, J. Liang and Z. Tong, "Explore the creative potential of undergraduates : improve the consciousness of innovation and practical ability" Computer Education, vol 19, 2009, pp.4-9.

\section{Authors}

Shanshan Li: Born in 1979. Master Degree of CS. Work in Department of Computer Science and Technology, Tsinghua University in Beijing, China. Engaged in experimental teaching research of Computer Science.

Ninghan Zheng: Born in 1979. Master Degree of CS. Work in Department of Computer Science and Technology, Tsinghua University in Beijing, China. Engaged in experimental teaching research of Computer Network and Embedded System.

Chengbin Quan: Born in 1972. PhD in CS. Work in Department of Computer Science and Technology, Tsinghua University in Beijing, China. Engaged in experimental teaching research of Computer Science.

Yongqiang Chen: Born in 1978. Master Degree of CS. Work in Department of Computer Science and Technology, Tsinghua University in Beijing, China. Engaged in experimental teaching research of Computer Science.

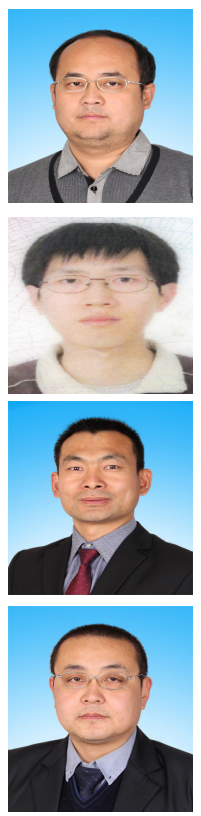

